\title{
MINERALOGIA E MOBILIDADE DE CATIONS DE UMA ALTERAÇÃO INTEMPÉRICA DE DIABÁSIO
}

\author{
C.A. CLEMENTE; A. MARCONI \\ Departamento de Ciencia do Solo-ESALQ/USP - C.P. 9, CEP: 13418-900 - Piracicaba,SP
}

\begin{abstract}
RESUMO: Em uma sequiência de alteraçāo intempérica de diabásio, situada no município de Capivari, SP, foram estudadas a mobilidade de cations liberados no processo e a evoluçẫo mineralógica ocorrida. A sequencia situa-se em condiçōes de clima sub-tropical semi-úmido e de boa drenagem. A mineralogia do diabásio, constituída essencialmente de plagioclásios e piroxénios, evoluiu para uma mineralogia simples, onde ma fração argila do solo ocorre apenas a caulinita, associada a bxidos de ferro, que nåo foram determinados. Vermiculita ocorre nas fases intermediárias, como o único argilomineral 2:1. A lixiviação de cátions solúveis ocorre já nos primeiros estágios do processo, seguidos da salica, também com remoção rápida, mas que, em face de seu elevado teor na rocha de origem, permanece maior tempo no sistema, permitindo a genese da caulinita e também de quartzo em pequena quantidade. Alumínio e ferro são imobilizados no sistema, o alumínio como constituinte de caulinita e o ferro como oxido. Descritores: diabásio, intemperismo de rochas
\end{abstract}

\section{MINERALOGY AND CATION MOBILITY OF A WEATHERING ALTERATION OF DIABASE}

\begin{abstract}
The mobility of the main cations and the mineralogical evolution are studied for a weathering sequence of a diabase, from unaltered rock to the rock-derived soil. The diabase is located in conditions of subhumid and subtropical weather, having good drainage, located in Capivari (SP), Brazil. The mineralogy of diabase, essentialy constitued of plagioclases and pyroxenes, developed to a simple mineralogy, in which the clay fraction of the soil consists only of kaolinite, associated to non determined iron oxides. Vermiculite occurs in the intermediary stages, as the only 2:1 clay mineral. The leaching of soluble cations occurs rapidly in the first stages of the process, followed by silica, also with rapid removal, however due to its high concentration in the original rock, it remains longer time in the system, in the structure of kaolinite and also as quartz in small quantity. Aluminium and iron are immobilized in the system, aluminium in the structure of kaolinite and iron as oxide.
\end{abstract}

Key Words: diabase, rock weathering

\section{INTRODUÇÃO}

A remoção de rochas basálticas e sedimentares ocorrida na depressão periférica do Estado de São Paulo, devido a processos pretéritos de intemperização e erosão, expôs na superfície o diabásio, na forma de sills e diques, que por sua vez, originaram solos de alta fertilidade natural e que se tornaram os mais importantes no desenvolvimento das culturas agrícolas do estado. A gênese desses solos tem atraído a atenção de diversos pesquisadores, que estudaram tanto a geoquímica, como a evolução mineralógica das rochas envolvidas no processo (MONIZ \& JACKSON, 1967; KLAMT, 1969; MELFI \& LEVI, 1971; LEVI \& MELFI, 1972; MONIZ et al., 1973; FORMOSO \& PINTAUDE, 1978; MOLLER \& KLAMT, 1982; MENEGOTO, 1983; DEMATTE \& MARCONI, 1991; DEMATTÊ et al., 1991), trazendo novas luzes ao conhecimento a evolução desses solos. A região de Piracicaba, no estado de São Paulo, na qual se insere o município de Capivari, é particularmente rica na presença de sills de diabásio, tendo como conseqüência grande área coberta por solos resultantes da intemperização dessas rochas. A exposição de uma intrusão de diabásio em sedimentos do Grupo Tubarão, no município de Capivari,SP, permitiu, neste trabalho, acompanhar o desenvolvimento mineralógico e a mobilidade dos cátions, durante o processo de intemperização, desde a rocha íntegra até o solo formado, em condições de boa drenagem.

\section{MATERIAL E MÉTODOS}

O perfil estudado está localizado no município de Capivari, SP, no $\mathrm{km} \mathrm{124,3} \mathrm{da} \mathrm{estrada}$ do Açúcar, situado em local de meia encosta, de relevo suave ondulado. $O$ diabásio pertence a Formação Serra Geral, Grupo São Bento e encontra-se 
atualmente exposto, devido a processos pretéritos de denudação, embutido em folhelhos da Formaçăo Itararé, Grupo Tubarão. A região apresenta clima subtropical de inverno seco, com temperatura média mínima inferior a $18^{\circ} \mathrm{C}$ e máxima superior a $22^{\circ} \mathrm{C}$. A precipitação média anual está entre 1.100 e $1.700 \mathrm{~mm}$, concentrada nos meses de verão (BRASIL, 1960).

As amostras foram coletadas em um perfil recentemente exposto, na sequência seguinte: 1: rocha integra, sem sinais aparentes de decomposição. 2: rocha semi-decomposta, em início de decomposição e descoloração, mas ainda preservando estrutura e textura originais. 3 : rocha moderadamente decomposta, com esfoliação esferoidal, mas ainda mostrando sinais de estrutura e textura originais. Apresenta superfície friável, com núcleo coeso. 4: Alterita com coloração bege, totalmente friável, apenas com vestígios muito vagos da estrutura original. 5: Alterita bege amarelada, totalmente friável. 6: Horizonte $\mathrm{C}$ do solo, de coloração amarelada. Amostra 7: Horizonte B do solo, coloração vermelho-escura, mostrando estrutura em blocos sub-angulares.

Como o solo está sendo cultivado há muitos anos com cana de açúcar, o horizonte $A$ foi descartado, a fim de evitar possíveis interferências do seu manuseio nos resultados obtidos.

Após a eliminação da matéria orgânica e dos óxidos de ferro das amostras friáveis (JACKSON, 1969), as frações argila e silte foram separadas por sifonação e a areia por tamização. Amostras das frações argila foram saturadas com $\mathrm{K}^{+} \mathrm{e}$ com $\mathrm{Mg}^{2+} \mathrm{e}$ irradiadas com raios- $\mathrm{x}$, utilizando-se tubo de cobre e filtro de níquel, no intervalo $2 \theta$ de 3 a $32^{\circ}$. As amostras saturadas com $\mathrm{K}^{+}$foram também aquecidas a 350 e $550^{\circ} \mathrm{C} \mathrm{e}$ as saturadas com $\mathrm{Mg}^{2+}$ foram tambem glicoladas (JACKSON, 1969). As amostras não friáveis foram moídas e irradiadas no intervalo $2 \theta$ de 3 a $62^{\circ}$. No reconhecimento dos minerais foram utilizados dados fornecidos por GIESEKING (1975) e por DIXON E WEED (1977). Os minerais da fração areia foram separados, através de bromofórmio, em leves e pesados e reconhecidos em microscópio polarizante. Não se efetuou a contagem de um número fixo de grânulos por lâmina, uma vez que apenas uma avaliação quantitativa foi suficiente para a caracterização das amostras. Também foram confeccionadas lâminas de seçōes delgadas da rocha não alterada, para exame em microscópio polarizante, onde, por contagem de pontos, foi possível determinar quantitativamente os minerais presentes. Para a análise química, as amostras sofreram fusão com $\mathrm{Na}_{2} \mathrm{CO}_{3}$. Cálcio, magnésio e ferro total foram determinados por espectrofotometria de absorção atômica, potássio por fotometria de chama, titânio por colorimetria, alumínio por volumetria e sílica por gravimetria. O sódio foi determinado por fotometria de chama, após ataque fluoridrico das amostras e o ferro bivalente por volumetria, após ataque nitroperclórico. 0 ferro trivalente foi calculado por diferença entre o ferro total e o bivalente. A análise granulométrica das amostras friáveis foi realizada utilizando método de KILMER E ALEXANDER (1949).

\section{RESULTADOS E DISCUSSÃO}

Os resultados obtidos na análise granulométrica (TABELA 1) mostram aumento da fração argila, consequência da evolução natural das frações mais grosseiras para as mais finas, devido à destruição de minerais primários intemperizáveis e formação de minerais secundários, de natureza argilosa. Observa-se que, da amostra 4 à amostra 6, a fração areia sofreu redução a silte, não ocorrendo, porém, mudanças acentuadas nos teores da fração argila. Entretanto, da amostra 6 para a amostra 7, tanto a fração areia como a fração silte reduziram-se sensivelmente, em favor do aumento da argila, que nesta amostra atingiu $50 \%$ do total. Em processos de decomposição de rochas esse efeito é esperado, mas em rochas básicas ele é mais pronunciado, motivado pela constituição mineralógica da rocha, quase totalmente formada por minerais primários facilmente decomponíveis, como são os plagioclásios calco-sódicos e os minerais ferromagnesianos, principais minerais constituintes da rocha em questão.

A mineralogia da rocha não alterada (amostra 1) foi estudada por microscopia ótica em lâminas de secção delgada e por análise de raios-x (Figura 1). A contagem de pontos na lâmina de microscopia mostrou que o diabásio é constituído de $43 \%$ de plagioclásios, com predominância de labradorita, reconhecida pelo pico a $0,32 \mathrm{~nm}, 48 \%$ de piroxênios, que predominam na lâmina, ocorrendo em maior quantidade a pigeonita, reconhecida pelos picos a 0,30 , e $0,21 \mathrm{~nm}$ e $9 \%$ de minerais opacos (magnetita e ilmenita). MELFI、\& GIRARDI (1962), em um sill de diabásio no município de Igarapava, SP, identificaram também a labradorita como o principal plagioclásio presente, mas, entre os piroxênios, observaram a predominância de augita sobre pigeonita. 
DEMATTE \& MARCONI (1991), em amostra de diabásio do município de Piracicaba, SP, encontraram alta predominância de plagioclásios (56\%) sobre piroxênios (25\%), estes principalmente augita.

TABELA 1 - Resultados percentuais de análise granulométrica de amostras de alteração de diabásio no município de Capivari, SP.

\begin{tabular}{lrrrrrr}
\hline Amostra & $\begin{array}{c}\text { areia } \\
\text { grossa }\end{array}$ & $\begin{array}{c}\text { areia } \\
\text { fina }\end{array}$ & $\begin{array}{l}\text { areia } \\
\text { total }\end{array}$ & silte & argila & total \\
\hline 4 & 23,6 & 23,2 & 46,8 & 41,2 & 12,0 & 100,0 \\
5 & 22,5 & 18,9 & 41,4 & 49,0 & 9,6 & 100,0 \\
6 & 18,1 & 18,3 & 36,4 & 51,0 & 12,6 & 100,0 \\
7 & 7,9 & 7,8 & 15,7 & 33,8 & 50,5 & 100,0 \\
\hline
\end{tabular}

Um mineral de coloração verde, situado entre os grânulos de piroxênios, com sinal ótico negativo, ângulo $2 \mathrm{~V}$ extremamente pequeno $e$ pleocroismo bem pronunciado, variando de incolor a verde, mostra características de vermiculita, o que é confirmado pelos resultados de raios- $x$, que mostram pico a $1,52 \mathrm{~nm}$, na amostra $\mathrm{Mg}$ glicolada (Figura 6), decrescendo a $1,29 \mathrm{~nm}$, quando tratada com potássio e aquecida a $250^{\circ} \mathrm{C}$ e a $1,00 \mathrm{~nm}$, quando aquecida a $350^{\circ} \mathrm{C}$ (Figura 3), resultados coincidentes com os obtidos por WALKER (1975). Segundo WEAVER (1958), essas características identificam vermiculita de baixa carga, não resultante de alteração intempérica, mas provavelmente formada na fase final do resfriamento do magma, como consequência de ação hidrotermal sobre minerais ferro-magnesianos pre-existentes. Um mineral verde com características 6́ticas semelhantes as do mineral aqui encontrado foi identificado por MELFI \& GIRARDI (1962) como clorofeita, em diabásio de Igarapava, SP.

A mineralogia da fração areia foi estudada em lâminas das frações leve e pesada, a partir da amostra 4, quando se obteve material suficiente para as análises.

$\mathrm{Na}$ fração leve, os plagioclásios, abundantes na amostra 4 e raros na amostra 7 , mostram sempre sinais de elevado estado de alteração. Grânulos de quartzo começam a surgir na amostra 6 e predominam na amostra 7, onde aparecem angulosos ou sub-angulosos, muitos com formas definidas de faces de cristal, denunciando pouco ou nenhum transporte.
A presença de grânulos subarredondados nessa amostra denuncia a contaminação de quartzo advindo de outras fontes, o que se torna perfeitamente possível, em face da ocorrência de sedimentos arenosos nas proximidades do local da amostragem.

Os resultados das lâminas de minerais pesados mostram a predominância absoluta de piroxênios na amostra 4, com nítidos sinais de estado avançado de decomposição, e poucos grânulos de minerais opacos (magnetita e ilmenita). Já na amostra 5 , os minerais opacos predominam, ocorrendo poucos piroxênios alterados. Essa predominância de opacos continua na amostra seguinte, onde ainda ocorrem raros grânulos de piroxênios, que desaparecem totalmente na amostra 7 , onde somente ocorrem minerais opacos. A presença de leucoxênio é rara, indicando que magnetita e ilmenita foram pouco afetadas pelo intemperismo.

$\mathrm{Na}$ fração argila, as figuras 2 a 6 mostram a evolução do intemperismo (amostras 2 a 7), com uma diminuição muito intensa de piroxênios e de plagioclásios já na amostra 3, mais rápida a dos piroxênios, que não mais existem na amostra 4 (Figura 1), enquanto que os plagioclásios resistem até a amostra 5, o que é de se esperar, uma vez que, segundo GOLDISH (1938), a labradorita é mais resistente que o piroxênio.

Por outro lado, verifica-se, na amostra 2, maior teor de vermiculita, observado pelo aumento na intensidade dos picos característicos deste mineral. $O$ aparecimento do pico a $1,00 \mathrm{~nm}$ na amostra aquecida a $550^{\circ} \mathrm{C}$ (Figura 4) denuncia a ocorrência de vermiculita dioctaédrica (SANTOS, 1975), que não aparece na rocha integra e que certamente deve ser produto de alteração intempérica. $O$ teor de vermiculita decresce a partir da amostra 3, mas seu desaparecimento somente ocorre no horizonte B do solo (amostra 7).

A presença de pico a $0,33 \mathrm{~nm}$ na amostra 2 (Figura 1) denuncia a ocorrência de quartzo, não observado na rocha não alterada (amostra 1). Essa ocorrência pode ser explicada por neoformação, devido à liberação de sílica na intemperização de plagioclásios e piroxênios, o que E perfeitamente aceito por diversos autores, como FLACH et al. (1969) e WILDING et al. (1977).

0 teor de quartzo na fraçâo argila aumenta com a evolução do intemperismo, até o horizonte B do solo (amostra 7), não podendo ser descartada a possibilidade, também, de adição desse mineral, oriundo de outras fontes, além de sua neoformação. 


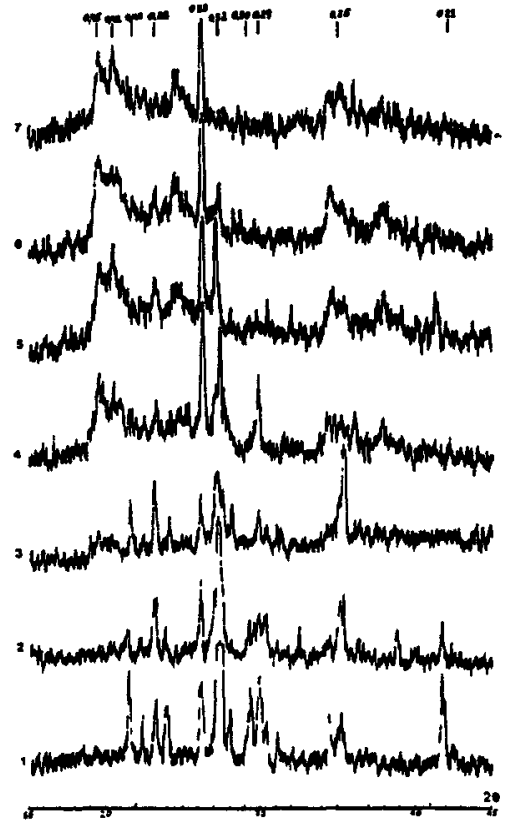

Figura 1. Difratogramas de amostras de alteração de diabásio do município de Capivari, SP, sem tratamento.

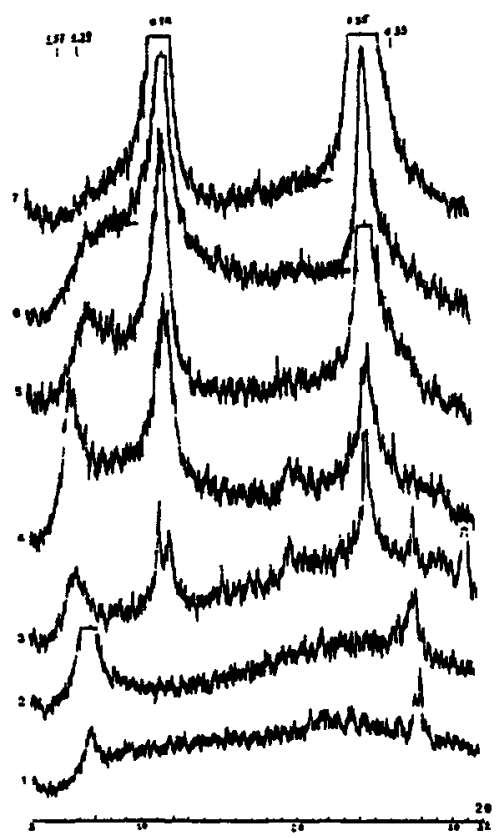

Figura 2. Difratogramas de amostras de alteração de diabásio do município de Capivari, SP, submetidas a tratamento com potássio, a temperatura de $25^{\circ} \mathrm{C}$.

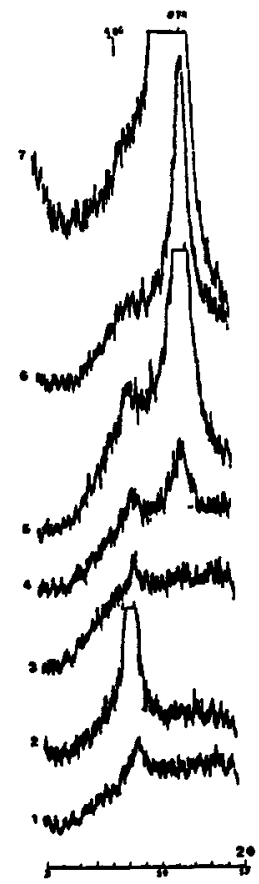

Figura 3. Difratogramas de amostras de alteração de diabásio no município de Capivari, SP, submetidas a tratamento com potássio, a temperatura de $350^{\circ} \mathrm{C}$.

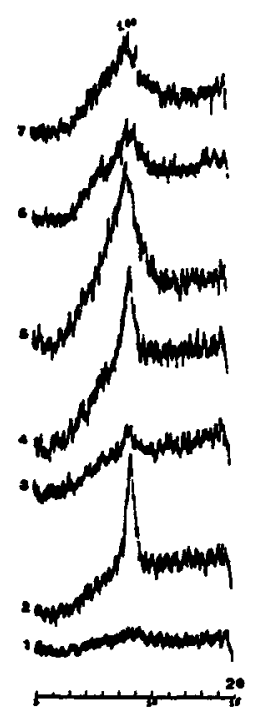

Figura 4. Difratogramas de amostras de alteração de diabásio do município de Capivari, SP, submetidas a tratamento com potássio, a temperatura de $550^{\circ} \mathrm{C}$. 


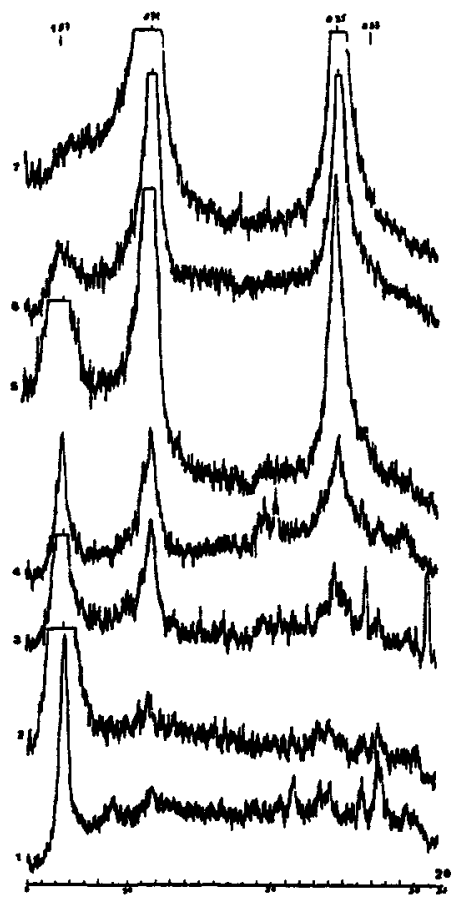

Figura 5. Difratogramas de amostras de alteração de diabásio do município de Capivari, SP, submetidas a tratamento com magnésio.

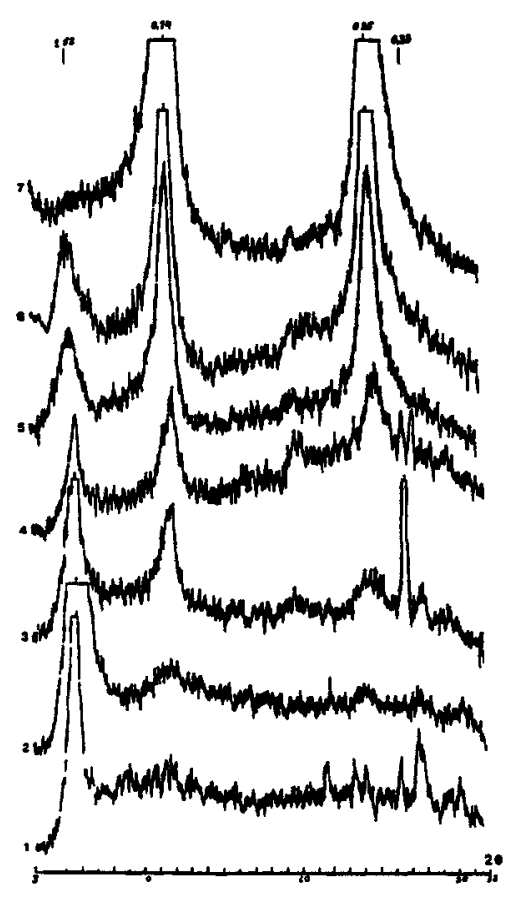

Figura 6. Difratogramas de amostras de alteração de diabásio do município de Capivari, SP, submetidas a tratamento com magnésio e glicoladas.

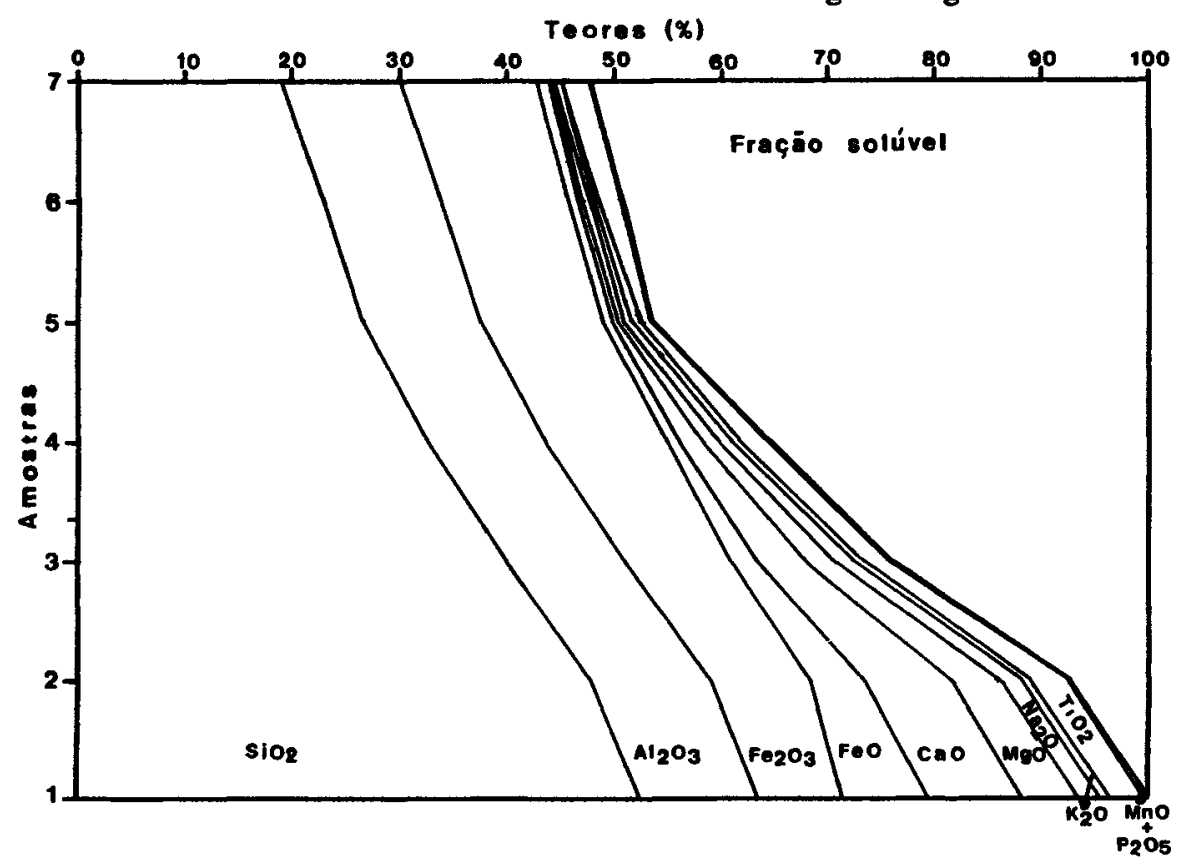

Figura 7. Evolução quantitativa de óxidos nas fases de alteração de diabásio no município de Capivari, SP (calculada pelo método do isoalumínio). 
A caulinita, mineral secundário resultante da alteração de minerais silicatados, começa a ocorrer com alguma intensidade a partir da amostra 4, caracterizada pelos picos a $0,74 \mathrm{~nm}$ e $0,34 \mathrm{~nm}$ (Figuras 3,5,6). Seu teor aumenta nas amostras seguintes, à medida que diminuem os teores dos minerais decomponíveis, plagioclásios, piroxênios e vermiculitas. A ausência de argilominerais de estrutura 2:1 pode ser explicada pela boa drenagem existente no sistema, responsável pela rápida lixiviação de cátions solúveis. A sílica também sofre intensa lixiviação, mas o alto teor inicial compensa essa lavagem, mantendo no ambiente concentração de sílica suficiente para a gênese de caulinita. Isto é confirmado pela ausência de gibsita em todas as fases do processo, o que indica que o teor de sílica é suficiente para impedir a sua formação. A TABELA 2 mostra a evolução mineralógica ocorrida nas diversas fases do processo.

Os resultados da análise química estão expressos na TABELA 3. Supondo-se que os teores de alumínio não devem mudar significativamente durante o processo de intemperização, por ser este elemento imobilizado no sistema (KRAUSKOPF, 1972), pode-se considerar, com pequena margem de erro, que o solo contém a mesma quantidade absoluta de alumínio que a existente na sua rocha de origem (GOLDISH, 1938; MONIZ et al., 1973). Desse modo, com base no teor de alumínio é possível calcular as quantidades absolutas dos outros constituintes durante as diversas fases do processo de intemperização da rocha e da formação do solo, o que também possibilita calcular o teor de resíduo detrítico remanescente (Figura 7) e avaliar a intensidade de remoção de cátions do sistema (Figura 8).

Os teores dos constituintes químicos, calculados pelo método do isoalumínio, expressos no TABELA 3 e na figura 7 mostram que, dos constituintes do diabásio de origem, apenas $47,6 \%$ permanecem como resíduo sólido no solo, tendo sido removidos do sistema $52,4 \%$ do material inicial, lixiviados na forma de sais solúveis.

$\mathrm{Na}$ primeira fase de alteração, da amostra 1 para a amostra 2, a lixiviação foi pequena, tendo sido eliminado apenas $7,5 \%$ do material inicial, acelerando-se as perdas rapidamente a partir daí, até o estágio atual.

Nessa primeira fase, dos cátions solúveis o $\mathrm{Fe}^{2+}$ foi o mais afetado, seguido de $\mathrm{Mg}$ e K. A seguinte sequência de remoção foi observada: $\mathrm{Fe}^{2+}$ $>\mathrm{Mg}>\mathrm{K}>\mathrm{Si}>\mathrm{Ca}>\mathrm{Na}$, mostrando que os minerais ferro-magnesianos foram os primeiros a sofrer os efeitos do intemperismo, confirmando o observado na análise mineralógica por raios $x$. As pequenas perdas de $\mathrm{Ca}$ e $\mathrm{Na}$ mostram que os plagioclásios, nesta primeira fase, foram pouco afetados pelo intemperismo.

A partir daí, a remoção dos cátions torna-se mais rápida e os cátions mais solúveis removidos com maior intensidade. A sequência de lixiviação nesta segunda fase de alteração passa a ser a seguinte: $\mathrm{Ca}>\mathrm{Mg}>\mathrm{Fe}^{2+}>\mathrm{Na}>\mathrm{Si}>\mathrm{K}$.

TABELA 2 - Evolução mineralógica de diabásio submetido a processo de intemperização, no município de Capivari, SP.

\begin{tabular}{|c|c|c|c|c|c|}
\hline Amostra & Plagioc. & Piroxen. & Vermic. & Quartzo & Caulen \\
\hline 1 & ++++ & +++++ & + & & \\
\hline 2 & $++t+$ & +++ & ++ & + & \\
\hline 3 & +++ & & + & + & + \\
\hline 4 & + & & + & + & + \\
\hline 5 & & & + & ++ & ++ \\
\hline 6 & & & + & ++ & $+t+$ \\
\hline 7 & & . & & ++ & +++1 \\
\hline
\end{tabular}

ANDERSON \& HAWKES (1958) encontram, em intemperização de rochas ácidas, maior mobilidade de $\mathrm{Ca}$ e $\mathrm{Mg}$ e menor de $\mathrm{K}$, o que ocorreu também na fase mais avançada da intemperização da rocha básica aqui estudada. Por sua vez, HYPOLITO \& VALARELLI (1973), em rochas básicas, encontram resultados discrepantes aos aqui apresentados, ao verificarem maior mobilidade de $\mathrm{K}$ e Na, já na fase inicial do processo. MARCONI (1991), em estudo de alteração de diabásio da mesma região, observa comportamento diferente apenas para $\mathrm{K}$, com menor mobilidade que $\mathrm{Na}$, na primeira fase e maior na segunda.

O comportamento da sílica mostra sua intensa remoção do sistema, numa taxa praticamente constante, mas, devido ao elevado teor inicial, sua concentração, em todas as fases, é maior que a dos outros elementos, tornando-se mais persistente no sistema.

A grande quantidade de silica removida mostra ser este componente altamente móvel, embora não atingindo valores equivalentes aos encontrados para os considerados cátions solúveis.

A maior solubilidade apresentada pela sílica em relação ao $\mathrm{Ca}$ e ao $\mathrm{Na}$, na fase inicial, deve ser consequência da liberação da sílica presente nos 

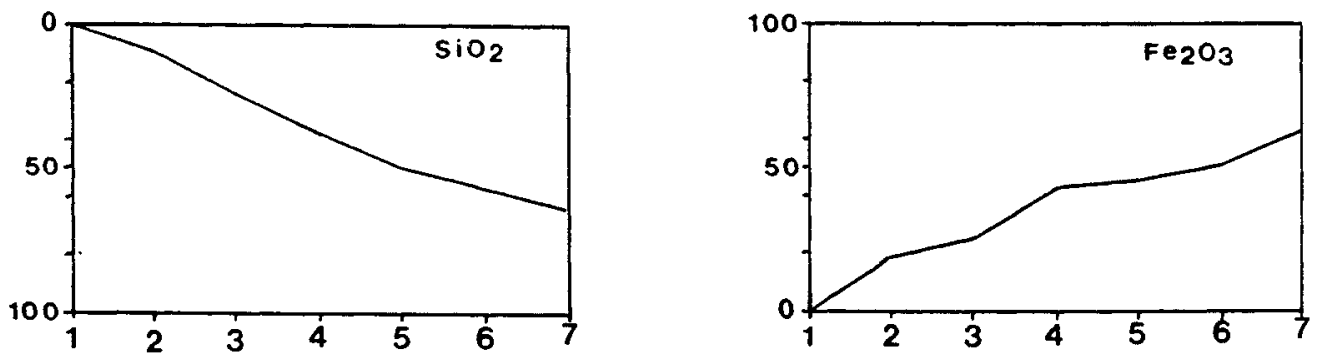

100
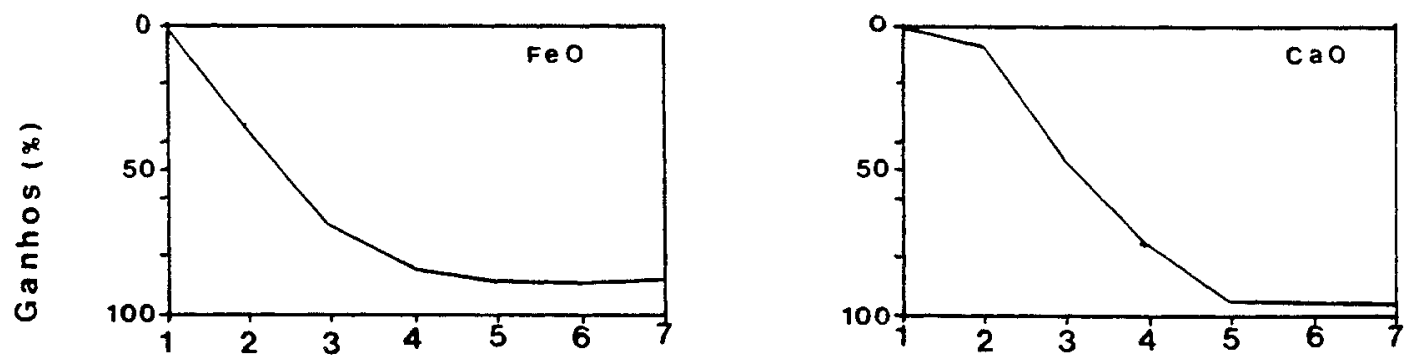

0
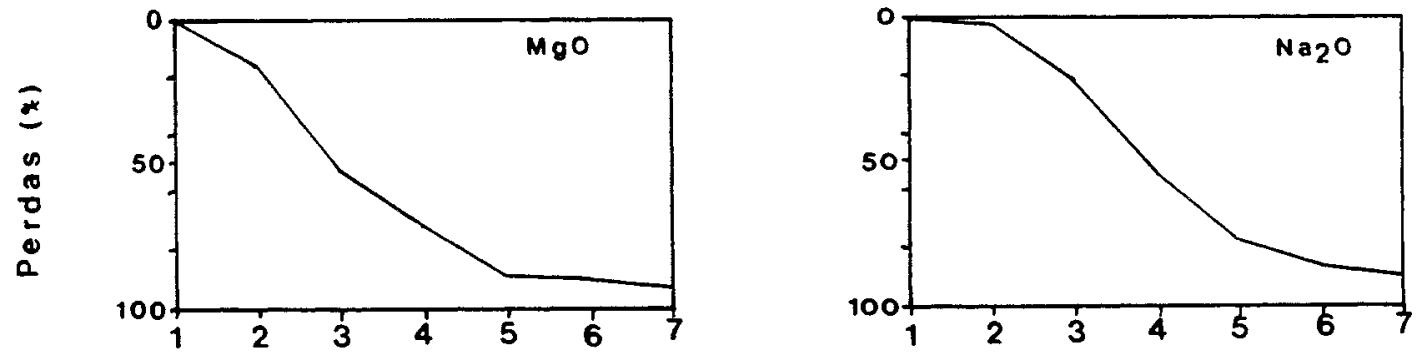

100
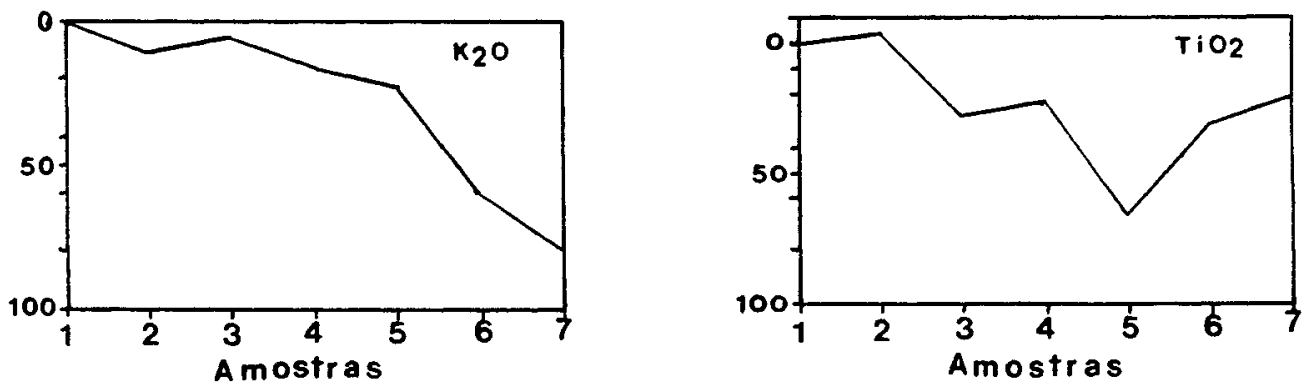

Figura 8. Curvas de ganhos e perdas (\%) dos óxidos nas fases de alteração de diabásio no município de Capivari, SP. 


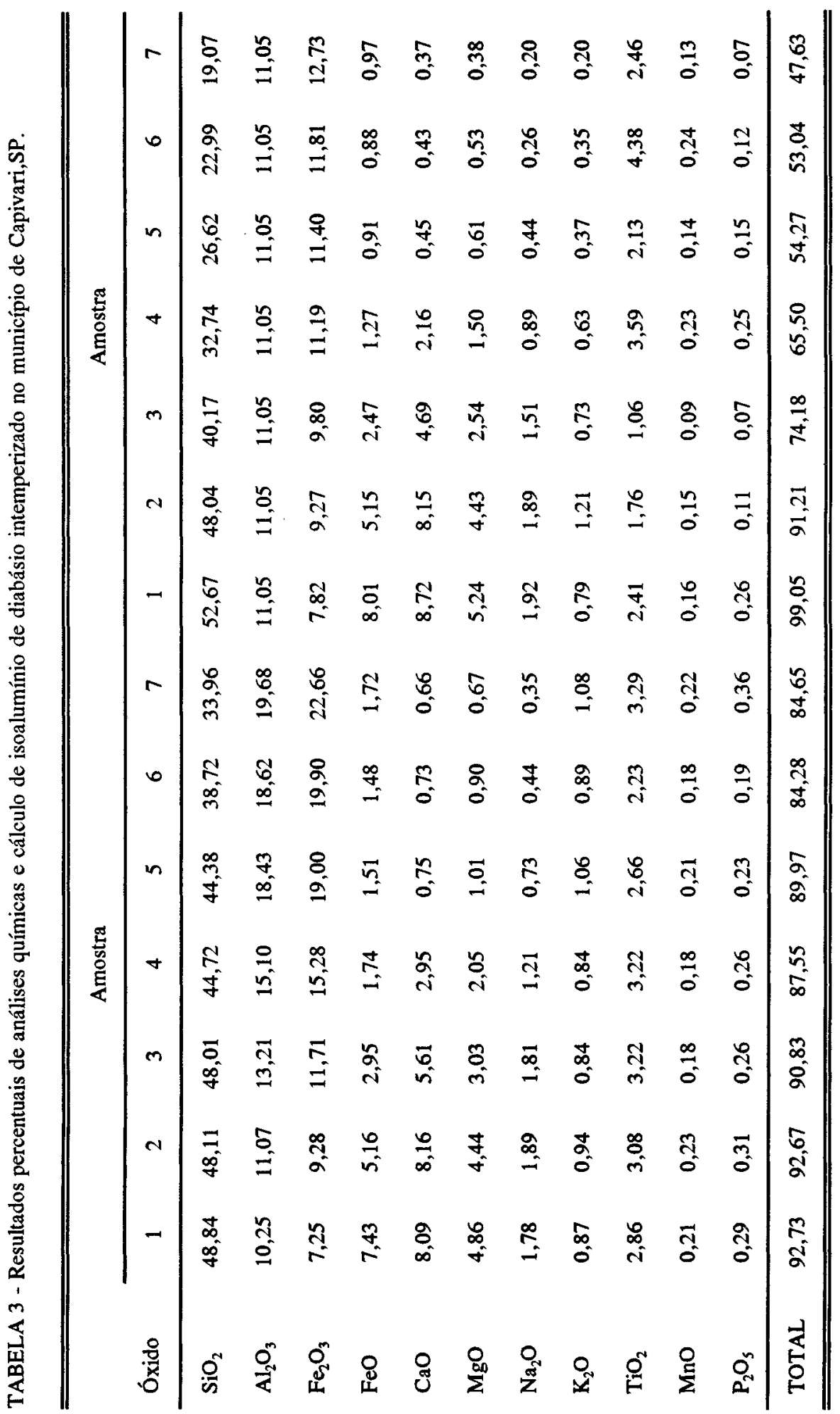


minerais ferro-magnesianos e da retenção do $\mathrm{Ca}$ e do $\mathrm{Na}$ nas estruturas dos plagioclésios, pouco atacados nessa fase. A partir de então, a sílica é lixiviada em menor proporção que aqueles elementos, devido à sua incorporação nas estruturas das argilas silicatadas (vermiculita e caulinita), por ocasião de sua formação.

Os óxidos considerados imobilizados no sistema, $\mathrm{Al}_{2} \mathrm{O}_{3}$ e $\mathrm{Fe}_{2} \mathrm{O}_{3}$, confirmam esse comportamento, apresentando aumento relativo de teores, ao longo de todo $o$ processo de intemperização. Todavia, se esse aumento pode ser considerado apenas relativo para $0 \mathrm{Al}_{2} \mathrm{O}_{3}$, o mesmo não acontece para $\circ \mathrm{Fe}_{2} \mathrm{O}_{3}$, que apresenta aumento real de teor, como consequência da oxidação do $\mathrm{Fe}^{2+}$, cujo desaparecimento do sistema é mais resultado de oxidação, que realmente de lixiviação (Figura 8). O $\mathrm{TiO}_{2}$, embora também considerado imobilizado no sistema, apresenta comportamento não compatível, já que mostra uma diminuição real de teor, culminando com a redução sensível na amostra 5 .

Os valores de $\mathrm{Ki}$ e das taxas de alteração (TABELA 4) confirmam a pouca alteração ocorrida na primeira fase e o grande incremento sofrido no processo a partir daí.

TABELA 4 - Resultados percentuais de análises químicas de extrato sulfúrico e valores de Ki e taxa de alteração de amostras alteradas de diabásio do município de Capivari, SP.

\begin{tabular}{|c|c|c|c|c|}
\hline Amostras & $\mathrm{SiO}_{2}$ & $\mathrm{Al}_{2} \mathrm{O}_{3}$ & $\begin{array}{r}\mathrm{Ki} \\
\%\end{array}$ & $\begin{array}{c}\text { Taxa alt. } \\
\%\end{array}$ \\
\hline 1 & 9,49 & 2,16 & 7,47 & 0,00 \\
\hline 2 & 10,35 & 2,45 & 7,18 & 3,85 \\
\hline 3 & 18,11 & 5,08 & 6,06 & 18,86 \\
\hline 4 & 28,46 & 11,95 & 4,05 & 45,79 \\
\hline 5 & 32,71 & 18,31 & 3,04 & 59,34 \\
\hline 6 & 30,32 & 18,49 & 2,79 & 62,68 \\
\hline 7 & 28,30 & 19,62 & 2,45 & 67,17 \\
\hline
\end{tabular}

O Ki final de 2,5 , na amostra 7 , está a indiçar a presença no solo de argilas de estrutura $2: 1$, associada a argilas $1: 1$, o que não foi confirmado pela análise mineralógica, onde nessa amostra apenas caulinita foi encontrada.

Este Ki indica uma taxa de alteração de apenas $67,2 \%$, o que mostra que o solo poderia ainda desenvolver um processo de alteração mais avançado. Entretanto, foi observada quantidade significativa de quartzo na fração argila, que deve ter sido solubilizado durante o ataque sulfúrico, aumentando o teor de sílica no extrato e, assim, influenciado o valor do Ki e da taxa de alteração.

\section{CONCLUSÕES}

O diabásio alterou-se para um sistema residual, onde permaneceu na fase final, o solo, menos de $50 \%$ do material de origem, com os cátions solúveis removidos intensamente, por um processo de drenagem eficiente.

Os cátions solúveis, cálcio, magnésio, sódio e potássio, foram removidos rapidamente, tornando-se praticamente ausentes no estágio final do processo. A sílica também mostrou rápida lixiviação, mas quantidade razoável ainda permaneceu no sistema, como conseqüência de seu elevado teor inicial. Os cátions considerados imóveis permaneceram no sistema, o ferro na forma de óxidos e o alumínio como constituinte da caulinita. Os principais minerais primários do diabásio intemperizaram-se rapidamente, primeiro os ferro-magnesianos e em seguida os feldspatos. Magnetita e ilmenita foram pouco afetados pelo intemperismo, permanecendo em grande quantidade entre os minerais pesados do solo. A mineralogia do estágio final do sistema é simples, ocorrendo em quantidade significativa apenas a caulinita como mineral da fração argila.

\section{REFERÊNCIAS BIBLIOGRÁFICAS}

ANDERSON, D.H.; HAWKES, H.E. Relative mobility of the common elements in weathering of somo schist and granite areas. Geochimica et Cosmochimica Acta, London, v.14, n.3. p.204-210, 1958.

BRASIL. Levantamento de reconhecimento de solos do Estado de São Paulo. Ministério da Agricultura. Serviço Nacional de Pesquisas Agronômicas, Rio de Janeiro, 1960. 634p. (Boletim Técnico, 12)

DEMATTÊ, J.L.I.; MARCONI, A. A drenagem na mineralogia de solos desenvolvidos de diabásio em Piracicaba(SP). Revista Brasileira de Ciência do Solo, Campinas, v.15, p.1-8, 1991.

DEMATTÊ, J.L.I.; MARCONI, A.; SPAROVEK, G.; TORRADO, P.V. Estimativa da evolução do intemperismo mediante ganhos e perdas de íons numa seqüência de solos desenvolvidos de diabásio e influenciados pela drenagem em Piracicaba, SP. Revista Brasileira de Ciência do Solo, Campinas, v.15, p.69-73, 1991 . 
DDXON, J.B.; WEED, S.B., (Ed.). Mineral in soil environments. Wisconsin: Soil Science Society of America, 1977. 948p.

FLACH, K.W.; NETTLETON, W.D.; GILE, L.H.; CADY, J.C. Pedocementation: Induration by silica, carbonates, and sesquioxides in the Quaternary. Soil Science, Baltimore, v.107, p.442-453, 1969.

FORMOSO, M.L.L.; PINTAUDE, D.A. Estudo da alteração do anortosito de Capivarita, Rio Pardo, R.S. Revista Brasileira de Geociências, São Paulo, v.8, n.3, p.180-205, 1978.

GIESEKING, J.E. Soil components. New York: Springer-Verlag, 1975, v.2, 684p.

GOLDISH, S.S. A study in rock-weathering. Journal of Geology, Chicago, v.46, p.17-58, 1938.

HYPOLITO, R.; VALARELLI, J.V. Ordem de remoção de elementos lixiviados em experiências de alteração. Boletim do Instituto de Geociências, São Paulo, v.4, p.47-51, 1973.

JACKSON, M.L. Soil chemical analysis: advanced course. Madison, Soil Science Society of America, 1969. 895p.

KILMER, V.J.; ALEXANDER, L.T. Method of making mechanical analysis of soils. Soil Science, Baltimore, v.68, n.1, p.15-26, 1949.

KLAMT, E. Morfologia, gênese e classificação de alguns solos do município de Ibimbá e regiôes onde ocorrem. Porto Alegre, 1969. 94p. Dissertação (Mestrado) Universidade Federal do Rio Grande do Sul.

KRAUSKOPF, K.B. Introdução à geoquímica. São Paulo: EDUSP, Polígono, 1972. v.1, 294p.

LEVI, F.; MELFI, A.J. Geochemical and mineralogical studies on the first stages of weathering of basic and related rocks. Revista Brasileira de Geociências, São Paulo, v.2, n.1, p.1-7, 1972.

MARCONI, A. Mobilidade de cátions em alteraçāo intempérica de diabásio no município de Rio das Pedras, SP. Anais da Escola Superior de Agricultura "Luiz de Queiroz", Piracicaba, v.48, p.211-222, 1991 .
MELFI, A.J.; GIRARDI, V.A.V. Ocorrência de um sill de diabásio no arenito Botucatu, município de Igarapava, SP. Boletim da Sociedade Brasileira de Geologia, São Paulo, v.11, n.2, p.55-70, 1962.

MELFI, A.J.; LEVI, F. Geochemical and mineralogical study on the first stages of weathering of basic and related rocks. Revista Brasileira de Geociências, São Paulo, v.1, n.1, p.22-28, 1971.

MENEGOTTO, E. Intemperização de rochas ultrabásicas no Rio Grande do Sul, Brasil. Revista Brasileira de Geociências, São Paulo, v.13, n.3, p.178-189, 1983.

MOLLER, M.R.F.; KLAMT, E. Identificação e gênese de argilominerais em latossolo roxo de Santo Ângelo (RS). Revista Brasileira de Ciência do Solo, Campinas, v.6, p.161-166, 1982.

MONIZ, A.C.; JACKSON, M.L. Quantitative mineralogical analysis of Brazilian soil derived from basic rocks and slate. Madison, Soil Science Society of America, 1967. (Report, 212).

MONIZ, A.C., NASCIMENTO, A.C.; PAIVA NETTO, J.E. Mobilidade dos constituintes de rochas básicas de São Paulo durante o intemperismo. Revista Brasileira de Geociências, São Paulo, v.3, n.3, p.201-213, 1973.

SANTOS, P.S. Tecnologia de Argilas Aplicada às Argilas Brasileiras. São Paulo: EDUSP, Edgard Blucher, 1975. v.1: Fundamentos, 340p.

WALKER, G.F. Vermiculites. In: GIESEKING, J.E. Soil components. New York, Springer-Verlag, 1975. v.2, p.155-189.

WEAVER, C.E. The effects and geologic significance of potassium fixation by expandable clay minerals derived from muscovite, biotite, chorite and volcanic material. American Mineralogist, Lancaster, v.43, p. $839-849,1958$.

WILDING, L.P., SMECK, N.E.; DREES, L.R. Silica in soils: quartz, cristobalite, tridymite and opal. In: DIXON, J.B.; WEED, S.B., (Ed.) Mineral in soil environments. Madison, Soil Science Society of America, 1977, p.471-542.

Enviado para publicação em 13.12 .93

Aceito para publicação em 22.06 .94 